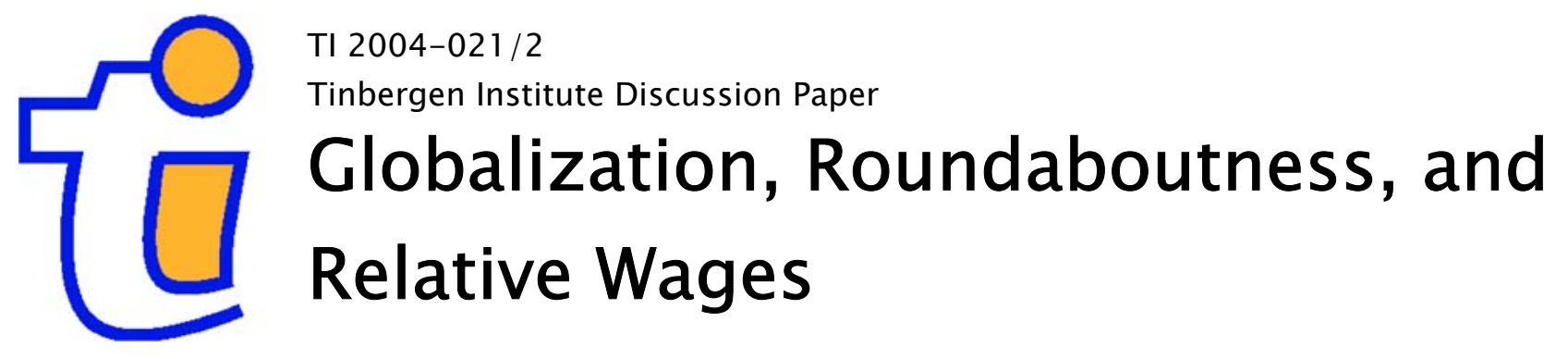

Joseph Francois'

Kevin Grier ${ }^{2}$

Douglas Nelson ${ }^{3}$

1 Faculty of Economics, Erasmus Universiteit Rotterdam, Tinbergen Institute, and CEPR,

2 University of Oklahoma,

3 Tulane University and Leverhulme Centre (Nottingham). 


\section{Tinbergen Institute}

The Tinbergen Institute is the institute for economic research of the Erasmus Universiteit Rotterdam, Universiteit van Amsterdam, and Vrije Universiteit Amsterdam.

Tinbergen Institute Amsterdam

Roetersstraat 31

1018 WB Amsterdam

The Netherlands

Tel.: $\quad+31(0) 205513500$

Fax: $\quad+31(0) 205513555$

Tinbergen Institute Rotterdam

Burg. Oudlaan 50

3062 PA Rotterdam

The Netherlands

Tel.: $\quad+31(0) 104088900$

Fax: $\quad+31(0) 104089031$

Please send questions and/or remarks of nonscientific nature to driessen@tinbergen.nl.

Most TI discussion papers can be downloaded at http://www.tinbergen.nl. 


\title{
Globalization, Roundaboutness, and Relative Wages ${ }^{\dagger}$
}

\author{
Joseph Francois \\ Tinbergen Institute \& CE PR \\ Kevin G rier \\ U niversity of 0 klahoma \\ D ouglas Nelson \\ Tulane U niversity \& \\ L everhulme $\mathrm{C}$ entre ( $\mathrm{N}$ ottingham)
}

February 2004

\begin{abstract}
We depart from the trade and wages literature and its emphasis on North-South trade, examining North-North by developing the basic linkages between trade-based integration and relative wages in an Ethier-type division of labor model. Using this model we identify a formal relationship between international trade, productivity, and wages. We then examine the trivariate relationship between trade, growth in total factor productivity (TFP), and the skill premium in a vector autoregression framework. We find evidence of a long-run relationship between growth in intermediate goods and changes in TFP. Controlling for this relationship we also find a positive relationship between trade and the skill-premium.
\end{abstract}

\section{JEL Codes: F16, F12}

Keywords: trade and wages, globalization, division of labor, monopolistic competition, intra-industry trade

† We thank Robert Baldwin and Glen Cain for their help in providing the wage series used in this paper and Tim Lloyd for valuable advice on the econometric analysis.

Address correspondence to: Prof. J. Francois, Faculty of Economics, Burg Oudlaan 50-H8-18, 3000D R Rotterdam, Netherlands.

Email: francois@ few.eur.nl fax: +31 104089146. 


\title{
Globalization, Roundaboutness, and Relative Wages
}

\begin{abstract}
We depart from the trade and wages literature and its emphasis on North-South trade, examining North-North by developing the basic linkages between trade-based integration and relative wages in an Ethier-type division of labor model. Using this model we identify a formal relationship between international trade, productivity, and wages. We then examine the trivariate relationship between trade, growth in total factor productivity (TFP), and the skill premium in a vector autoregression framework. We find evidence of a long-run relationship between growth in intermediate goods and changes in TFP. Controlling for this relationship we also find a positive relationship between trade and the skill-premium.
\end{abstract}

JEL Codes: F16, F12

Keywords: $\quad$ trade and wages, globalization, division of labor, monopolistic competition, intra-industry trade

\section{INTRODUCTION}

The growth in research on the link between trade and wages seems to be abating, and the collective prior among economists on the empirical magnitude of that link seems to have stabilized around the existence of some statistically significant but practically small effect of trade on the decline in the relative wage of unskilled workers. However, important questions remain. The great majority of both theoretical and empirical work addresses the link between trade and wages within the context of the Heckscher-O hlin-Samuelson (HO S) model, generalized in a variety of straightforward ways. This tends to focus attention on North-South trade, where the Stolper-Samuelson effects would be most pronounced. That is, given substantial liberalization in North-South trade and falling frictional costs of trade, the substantial differences in relative commodity and factor prices between North and South might cause us to expect large effects. However, as a number of students of this topic have pointed out, the volume of North-South trade is quite small, with the, somewhat controversial, implication that the leverage for Stolper-Samuelson effects is also small. Where we do observe substantial and 
growing trade volumes and deepening economic integration is between North (aka OECD) economies.

In this paper we make a significant departure from the emphasis of this literature. As with current empirical research on trade patterns, which has examined the implications of imperfect competition models, we provide an exploratory empirical analysis of a relatively simple monopolistic competition model of the link between trade and labour markets. ${ }^{1}$ Specifically, we examine, theoretically and empirically, North-North trade within a monopolistic competition model, looking for links between globalization and labour market performance.

Given the ease with which the HOS model yields an estimating framework, it is not surprising that the empirical literature on trade and wages has derived primarily from competitive models of the HOS family. By contrast, imperfectly competitive models come in a variety of forms, most of which do not yield as readily to empirical representation as do the competitive models. Nonetheless, this is not the first attempt to evaluate the links between trade and wages under conditions of imperfect competition. The closest empirical analysis to that presented here is Borjas and Ramey (1994). In that paper, the authors develop a simple theory of Nash bargaining between a firm and a union in an industry characterized by rents. ${ }^{2}$ Assuming an empirical connection between concentration and rents, the authors hypothesize that increased competition in concentrated sectors will shrink rents, reducing returns to labour in those sectors.

1 There is now considerable literature suggesting: 1) that the HOV model does a less than spectacular job in describing directions of trade; and that 2) alternatives including increasing returns and monopolistic competition offer a useful addition to factor-endowments in accounting for directions of trade. D aniel Trefler (1995; Antweiler and Trefler, 2002) has probably done more than anyone to advance this position, but the literature is now vast. Harrigan (2003) provides an overview of this research. Just as these models help account for the directions of trade, we suggest in this paper that the same class of models can help us understand the evolution of the relationship between trade and wages.

2 This is essentially the model developed in Brander and Spencer (1988). Alternative models of union preferences and of the underlying bargain, raising more-or-less the same questions as those in Borjas and Ramey, are developed in Grossman (1984); Mezzetti and Dinopoulos (1991); and Gaston and Trefler (1995). 
If unskilled workers are concentrated in sectors characterized by large rents and unions, increased competition in those sectors will cause the aggregate wage for unskilled workers to fall due to: a reduction in the wage premium via a change in the bargain; shrinkage in the size of the high wage sector; and increased supply of unskilled labour to other sectors. This structure is used to motivate a discussion of a time series analysis of the long-run relationship between net imports of trade in durable goods and the relative wage of skilled versus unskilled workers. The main empirical result is that "the durable goods deficit as a percent of GDP has the same long-run trend as the college premium from 1963 to 1988" (Borjas and Ramey, pg. 226). The results reported here also relate to the long-run relationship between trade volumes and wages at the macro level. However, the precise choice of variables will reflect a different theoretical framework.

One of the difficulties in interpreting the Borjas/ Ramey analysis is that the framework is essentially microeconomic, while the empirical analysis is macroeconomic. ${ }^{3}$ As a result, the theoretical link between a broad aggregate like trade volume and the economywide wage premium remains quite unclear. Feenstra and Hanson (1996) provide an alternative analysis, with a more fundamentally macroeconomic basis. In their model, falling costs of outsourcing allow firms to move the most labor-intensive part of their production process offshore, with the implication that the relative demand for unskilled labor (relative skilled labor) falls, leading to an increase in the skill premium. ${ }^{4}$ In

${ }^{3}$ By "microeconomic" we refer to the fact that the Borjas/ Ramey analysis is partial equilibrium in nature and extended to a claim about economywide effects by a number of auxiliary hypotheses of uncertain theoretical and empirical validity. A more natural empirical implementation of the underlying model would focus directly on the sector level, examining the relationship between trade, rents (or correlates such as concentration), union coverage, and wage premia. Interestingly, this is essentially what G aston and Trefler (1995) do, and their results are broadly supportive of models in which international competition suppresses rents that support payment of wage premia.

${ }^{4}$ Feenstra and Hanson (1996) are primarily interested in accounting for the fact of a rising skill premium in both North and South, so their model is simplified in ways that stress this phenomenon. In particular, they develop a one-sector economy with a continuum of inputs, and two countries. Feenstra and Hanson (1997) focus on the Mexican case, finding that FD I is positively associated with the skill premium there. It should be noted that similar implications can 
Feenstra and Hanson (1999) the authors use cross-sectional methods to examine the relationship between the wage premium and outsourcing as proxied by measures of intermediate import volumes. Among other important results, Feenstra and Hanson find that outsourcing has a sizable effect on relative wages. The empirical results reported here also emphasize trade in intermediate goods, though we focus on a more highly aggregated treatment of the economy and use time series methods.

A final body of work closely related to the present paper attempts to analyze the trade-wage relationship in a monopolistic competition/ division of labor framework. Building on the fundamental work of Ethier (1982) and Markusen (1990), Markusen and Venables $(1997,1999)$ develop a two-sector, two-factor theoretical model characterized by one conventional (i.e. constant returns to scale) sector and one sector characterized by monopolistic competition and division of labor induced external scale economies. ${ }^{5}$ As with the Feenstra/ Hanson analysis, Markusen and Venables are interested in North-South issues, so their two-country model involves endowment differences as well as the division of labor structure. Within this framework, the authors show that effects of a reduction in barriers to multinationalization have ambiguous effects on the wage premium. Using a similar production structure, Lovely and Nelson (2000) examine trade between similar countries and wages, Francois and Nelson (2001) analyze trade and foreign direct investment between similar countries, and its effect on the wage premium, and the recent book by Dluhosch (2000) and the paper by Burda and Dluhosch (2002) emphasize outsourcing and relative wages. Models of this last sort suggest a connection between the volume of trade in intermediate goods and relative wages. Thus, where Borjas/ Ramey analyze net trade in intermediate goods and Feenstra/ Hanson analyze imports of intermediate goods, we will be analyzing global trade in intermediate goods.

emerge in models of outsourcing based on more conventional trade models. See, for example, Jones and Kierzkowski (2001), D eardorff (2001), and Kohler (2003).

${ }^{5}$ See Francois and Nelson (2002) for an expository development of this class of model. 
This paper is organized as follows. In Section 2 we develop the basic linkages between trade-based integration and relative wages in an Ethier-type division of labor model. This points to a relationship between integration, productivity, and wages. In Section 3 we examine the trivariate relationship between trade, growth in total factor productivity (TFP), and the skill premium in a vector autoregression framework. We find evidence of a long-run relationship between growth in intermediate goods and changes in TFP. There is also evidence of a positive relationship between trade and the skill premium. In Section 4 we conclude.

\section{Globalization, Roundaboutness, and Wage Mechanics}

We start with an examination of the linkages between relative wages and trade in a division-of-labor model along the lines of Ethier (1982). O ur starting point is returns related to the international division of labour. While the notion that the division of labour has both micro and macroeconomic foundations goes back at least to Adam Smith, and most clearly to Allyn Young, it lived a shadowy existence until the development of a number of simple formalisations in the early 1980s permitted direct introduction of these ideas into the main corpus of economic theory. ${ }^{6}$ One of the fundamental barriers to formalization lay in the difficulty of treating the macroeconomic aspect of division of labour seriously in a tractable framework. The macroeconomic aspect of the analysis rests on the recognition that an increasing division of labour involves a fundamental transformation of technology (increasing "roundaboutness") at the level of the economy as a whole. In addition, as we are now well aware, any serious treatment of the macroeconomic aspects of the division of labour leads fairly directly to increasing returns and thus to non-convexities in the feasible set.

${ }^{6}$ Buchanan and Yoon (1994) collect a number of key papers from both the shadowy early period (including the relevant passage from Smith, and Young's classic essay) and the current emergence as a core element of both micro and macroeconomic research. Krugman's (1995) O hlin Lectures are a fascinating presentation of the relationship between ideas and models in this area. 
The key step in formalizing these essential notions was Wilfred Ethier's insight that the Spence-Dixit-Stiglitz model of monopolistic competition could be reinterpreted as a model of the division of labour. In addition to a perfectly competitive, constant returns to scale sector, the Ethier model has a sector that uses specialized inputs to produce a final consumption good. Allyn Young-like roundaboutness is represented by the fact that productivity in this sector is increasing in the variety of such inputs. On the other hand, the division of labour among producers of specialized inputs is limited by increasing returns and fixed resources. ${ }^{7}$ As was clear from the start of this literature, this model was characterized by macroeconomic increasing returns as well as the microeconomic increasing returns at the level of specialized inputs. ${ }^{8}$

We first assume a numeraire good $\mathrm{W}$ produced with a standard neoclassical technology and employing two factors: skilled labor $\mathrm{S}$ and unskilled labor L.

$$
W=f\left(L_{W}, S_{W}\right), f_{L}, f_{S}>0, f_{L L}, f_{S S}<0
$$

In addition, skilled and unskilled labor can be employed in the manufacturing sector. This involves Ethier-type assembly of specialized intermediate goods under a CES technology:

$$
M=\left[\sum_{i=1}^{n} x_{i}^{\rho}\right]^{1 / \rho}, 0<\rho<1
$$

TThis aspect of the model was also essential to the model of Spence (1976) and Dixit-Stiglitz (1977). In the SD S model these are final consumption goods, while in the Ethier model they are producer goods.

8In addition to Ethier's original analysis, see Markusen (1990) and Francois and Nelson (2002) for treatments that stress the division of labour/ macroeconomic increasing returns aspects of the Ethier model. This property of the Ethier model also led to its adoption as the theoretical basis of one of the fundamental models of endogenous growth (e.g. Romer, 1987). 
In equation (2), intermediate goods $\mathrm{x}$ are indexed over $\mathrm{n}$ varieties. We assume symmetric and homothetic cost structures for the production of intermediate goods. In particular,

$$
c\left(x_{i}\right)=\left[a+b x_{i}\right] p_{m}
$$

where $p_{m}$ is the price of factor bundles used for the production of manufactured goods. The technology for production of factor bundles $\mathrm{m}$ is itself a standard neoclassical technology.

$$
m=h\left(L_{m}, S_{m}\right)
$$

The economy, expressed in terms of the transformation technology for $\mathrm{W}$ and $\mathrm{m}$, is strictly Heckscher-O hlin. As such, we have full employment of factors.

$$
\begin{aligned}
& L=L_{m}+L_{W} \\
& S=S_{m}+S_{W}
\end{aligned}
$$

It follows that in reduced form we can specify the transformation frontier between bundles and wheat as an artifact of equations (1), (4), (5), and (6). This is formalized as equation (7).

$$
m=g(W) \quad g^{\prime}<0, g^{\prime \prime}<0
$$

The market for intermediates is assumed to be monopolistically competitive. Given our specification of equations (2), (3) and (4), we are therefore able to specify the transformation technology from intermediate bundles to final manufactured goods in terms of a multiplier $\theta$ that is a function of the total scale of domestic and foreign production of intermediates $m$ and $\mathrm{m}^{*}$, 
and also of a Samuelson trading cost coefficient $\tau$. This is expressed formally in equations (8) and (9). (Francois and Nelson, 2002).

$$
\begin{gathered}
\theta=\theta\left(m, m^{*}, \tau\right)>0, \frac{\partial \theta}{\partial m}>0, \frac{\partial \theta}{\partial m^{*}}>0, \frac{\partial \theta}{\partial \tau}<0 \\
M^{s}=\theta m
\end{gathered}
$$

The price of intermediate bundles $m$ can be expressed as a function of our location on the transformation curve between $\mathrm{m}$ and $\mathrm{W}$. Combined with average cost pricing of manufactured intermediates, we can then, in turn, specify the supply price of manufactured goods in terms of the multiplier $\theta$ and the price of intermediates.

$$
\begin{gathered}
p_{m}=-\left(h^{\prime}\right)^{-1} \\
p_{M}=\theta^{-1} p_{m}=-\left(h^{\prime} \theta\right)^{-1}
\end{gathered}
$$

To close our model of the economy, we assume homothetic preferences. As such, the expenditure share of manufactured goods $\alpha$ will be a function of the relative price of manufactured goods $p_{M}$, while demand will be a function of relative prices and total income $G$. Income will itself be a function of relative prices and the trading cost.

$$
\begin{gathered}
\alpha=j\left(p_{M}\right), j_{p_{M}}<0 \\
G=G\left(p_{M}, \tau\right) \\
M^{d}=Z(\alpha, G)
\end{gathered}
$$

To explore the impact of deeper integration as proxied by falls in the trading cost coefficient $\tau$, we first totally differentiate the supply side of the system (equations 7, 8, 9, 10,11). This yields equations (15)-(19). 


$$
\begin{gathered}
\hat{W}=\varepsilon_{W, m} \hat{m} \\
\hat{\theta}=\varepsilon_{\theta, m} \hat{m}+\varepsilon_{\theta, m^{*}} \hat{m}^{*}+\varepsilon_{\theta, \tau} \hat{\tau} \\
\hat{p}_{m}=\frac{h^{\prime \prime} W}{h^{\prime}} \hat{W} \\
\hat{p}_{M}=-\hat{\theta}+\hat{p}_{m}=-\hat{\theta}+\frac{h^{\prime \prime} W}{h^{\prime}} \hat{W} \\
=-\left(\varepsilon_{\theta, m} \hat{m}+\varepsilon_{\theta, m^{*}} \hat{m}^{*}+\varepsilon_{\theta, \tau} \hat{\tau}\right)+\frac{h^{\prime \prime} W}{h^{\prime}} \hat{W} \\
=-\left(\varepsilon_{\theta, m} \hat{m}+\varepsilon_{\theta, m^{*}} \hat{m}^{*}+\varepsilon_{\theta, \tau} \hat{\tau}\right)+\frac{h^{\prime \prime} W}{h^{\prime}} \varepsilon_{W, m} \hat{m} \\
\hat{M}^{s}=\hat{\theta}+\hat{m}
\end{gathered}
$$

Throughout $\hat{x}=\partial x / x$ indicates a proportional change in $\mathrm{x}$, while $\varepsilon_{x, y}=(\partial x / \partial y)(y / x)$ indicates the elasticity of $\mathrm{x}$ with respect to $\mathrm{y}$.

We also differentiate the demand side of the system, again expressing our results in percent change terms. From equations (12)-(14), we obtain equations (20)-(22).

$$
\begin{gathered}
\hat{\alpha}=\varepsilon_{\alpha, p_{M}} \hat{p}_{M} \\
\hat{G}=\varepsilon_{G, p_{M}} \hat{p}_{M}+\varepsilon_{G, \tau} \hat{\tau} \\
\hat{M}^{d}=\varepsilon_{Z, \alpha} \hat{\alpha}+\varepsilon_{Z, G} \hat{G}
\end{gathered}
$$

We start with a symmetric equilibrium to stress the point that even between identical economies, there are linkages between trade, productivity and production patterns, and wages in division of labor models. As such, rest of world values mirror home country values, and we can focus on home demand and supply conditions. D eparture from symmetry is then discussed afterwards. With appropriate substitutions, we solve for the change in the size of the manufacturing sector $\hat{m}$. First, we substitute equation (17) into equations (20) and (21). This in turn we substitute into equation (22), yielding equation (23). 


$$
\begin{aligned}
\hat{M}^{d}= & \varepsilon_{Z, \alpha} \varepsilon_{\alpha, p_{M}}\left(-\left(\varepsilon_{\theta, m} \hat{m}+\varepsilon_{\theta, m^{*}} \hat{m}^{*}+\varepsilon_{\theta, \tau} \hat{\tau}\right)+\frac{h^{\prime \prime} W}{h^{\prime}} \varepsilon_{W, m} \hat{m}\right) \\
& +\varepsilon_{Z, G} \varepsilon_{G, p_{M}}\left(-\left(\varepsilon_{\theta, m} \hat{m}+\varepsilon_{\theta, m^{*}} \hat{m}^{*}+\varepsilon_{\theta, \tau} \hat{\tau}\right)+\frac{h^{\prime \prime} W}{h^{\prime}} \varepsilon_{W, m} \hat{m}\right)+\varepsilon_{G, \tau} \hat{\tau}
\end{aligned}
$$

On the supply-side, we substitute equation (16) into (19), yielding equation (24).

$$
\hat{M}^{s}=\varepsilon_{\theta, m} \hat{m}+\varepsilon_{\theta, m^{*}} \hat{m}^{*}+\varepsilon_{\theta, \tau} \hat{\tau}+\hat{m}
$$

Setting equation (23) equal to equation (24), we then obtain equation (25).

$$
\begin{aligned}
\varepsilon_{\theta, m} \hat{m}+ & \varepsilon_{\theta, m^{*}} \hat{m}^{*}+\varepsilon_{\theta, \tau} \hat{\tau}+\hat{m} \\
=\quad & \varepsilon_{Z, \alpha} \varepsilon_{\alpha, p_{M}}\left(-\left(\varepsilon_{\theta, m} \hat{m}+\varepsilon_{\theta, m^{*}} \hat{m}^{*}+\varepsilon_{\theta, \tau} \hat{\tau}\right)+\frac{h^{\prime \prime} W}{h^{\prime}} \varepsilon_{W, m} \hat{m}\right) \\
& +\varepsilon_{Z, G} \varepsilon_{G, p_{M}}\left(-\left(\varepsilon_{\theta, m} \hat{m}+\varepsilon_{\theta, m^{*}} \hat{m}^{*}+\varepsilon_{\theta, \tau} \hat{\tau}\right)+\frac{h^{\prime \prime} W}{h^{\prime}} \varepsilon_{W, m} \hat{m}\right)+\varepsilon_{G, \tau} \hat{\tau}
\end{aligned}
$$

In the fully symmetric equilibrium, where $m=m^{*}$, we can simplify equation (25) and re-arrange it as follows:

$$
\begin{gathered}
\varepsilon_{m, \tau}=\frac{\left(\varepsilon_{G, \tau}-\varepsilon_{\theta, \tau}-\varepsilon_{Z, \alpha} \varepsilon_{\alpha, p_{M}} \varepsilon_{\theta, \tau}-\varepsilon_{Z, G} \varepsilon_{G, p_{M}} \varepsilon_{\theta, \tau}\right)}{\varepsilon_{\theta, m}+\varepsilon_{\theta, m^{*}}+1+\left(\varepsilon_{Z, \alpha} \varepsilon_{\alpha, p_{M}}+\varepsilon_{Z, G} \varepsilon_{G, p_{M}}\right)\left(\left(\varepsilon_{\theta, m}+\varepsilon_{\theta, m^{*}}\right)-\frac{h^{\prime \prime} W}{h^{\prime}} \varepsilon_{W, m}\right)} \\
\operatorname{sign}\left(\varepsilon_{m, \tau}\right)=\frac{(?)+(-)(-)+(-)(+)(?)(-)+(-)(+)(?)(-)}{(+)+(+)+(+)+((+)(?)+(+)(?))((++)+(+))+(-)(+)(-))}
\end{gathered}
$$

There are three basic ambiguities that arise in signing of equation (26). First, the impact of trading costs on GDP $\varepsilon_{G, \tau}$ is in general ambiguous, though in a symmetric equilibrium we may assume this is negative. Second, the impact of the price of manufactures on GDP $\varepsilon_{G, p_{M}}$ is also generally ambiguous, both in the standard Heckscher-O hlin model and here. On the demand side, we have a final 
ambiguity related to the impact of price changes on expenditure shares $\varepsilon_{\alpha, p_{M}}$. While the impact on quantity demanded is direct with sufficient assumptions about normality of demand, the expenditure share may itself rise or fall as a result. This last effect is stressed by Lovely and Nelson (2000). The first two will depend on the underlying net export position of the economy, and the strength of agglomeration/ scale effects, with a trade-off emerging between scale effects and terms of trade effects. (See Francois 1994 on this trade-off outside the symmetric case). A further ambiguity follows when we depart from symmetric equilibria. As stressed by Francois and Nelson (2002), changes in m may lead to an increase or decrease in $\mathrm{m}^{*}$, further complicating the signing of a more general version of equation (26).

With an underlying Heckscher-O hlin technology for $\mathrm{m}$ and $\mathrm{W}$, relative wages for skilled and unskilled labor $\omega_{S}$ and $\omega_{U}$ will be a function of the size of the manufacturing sector as indexed by $\mathrm{m}$, while the impact of globalization (through trading costs $\tau$ ) on $\mathrm{m}$ will be ambiguous given equation (26).

$$
\begin{gathered}
\Omega=\frac{\omega_{S}}{\omega_{U}}=f(m) \\
\varepsilon_{\Omega, \tau}=\varepsilon_{\Omega, m} \varepsilon_{m, \tau} \leq 0 \\
(+)(?)
\end{gathered}
$$

At the same time, there is a direct impact of globalization on productivity, with $\theta$ rising with a fall in trading costs and the consequent rise in cross-border gross trade in intermediates, even in an otherwise symmetric equilibrium where we sterilize resource shifts.

In summary, deeper integration implies unambiguous rising productivity in the manufacturing sector, driving changes in relative wages related to consequent resource shifts. These wage effects are themselves theoretically ambiguous. Formally: 
Observation 1: Within the class of global division-of-labor (i.e. monopolistic competition) models, there is a positive structural link between global integration (through rising trade and investment levels) and manufacturing productivity.

Observation 2: Within the class of global division-of-labor (i.e. monopolistic competition) models, there is an ambiguous structural link between global integration (through rising trade and relative wages) and the skill premium. The direction of this link is ultimately an empirical question.

\section{SOME EMPIRICS}

In this section we examine the empirical relationship between trade, productivity, and the skill premium in an effort to evaluate the usefulness of Ethier-type models of the international division of labor as a framework for thinking about the trade-wages link. As with the macroeconomic predictions of endogenous growth theory and the new geography, both of which are based on essentially the same model as that developed in the previous section, compelling empirical tests are hard to conceive. The model in the previous section suggests that globalization, however defined, implies an expanded division of labor, potentially increasing demand for one class of labor relative to another. Thus we need to examine the relationship between increased trade (indirectly measuring the increased division of labor) and the relative wage. However, the model implies that this relationship is mediated by increased efficiency as a function of the expanding division of labor. Furthermore, because the relationship is derived in a comparative static fashion, there is a benefit from examining it in a time series framework that allows us to look at long and short run components. Before reporting our results, we first describe the data and the technique. 
O ur basic data on wages come from Baldwin and Cain (2000). ${ }^{9}$ We focus on unskilled workers defined as those workers possessing less than high school education (W ); and skilled workers defined as high school education or more $\left(\mathrm{W}_{\mathrm{s} 1}\right)$; and skilled workers defined as greater than high school education $\left(\mathrm{W}_{\mathrm{s} 2}\right)$. Logs of these series are shown in Figure 1. From these variables, we constructed two measures of the skill premium (i.e. the wage of skilled workers relative to unskilled workers): $\mathrm{SP} 1=\mathrm{W}_{\mathrm{s} 1} / \mathrm{W}_{\mathrm{u}}$ and $\mathrm{SP} 2=\mathrm{W}_{\mathrm{s} 2} / \mathrm{W}_{\mathrm{u}}$. Figure 2 shows logs of these series. The proximate spur to the boom in analysis of these series is illustrated in Figure 2, where we see both measures of the skill premium fall until about 1980, and then rise fairly dramatically.

O ur theoretical discussion suggests that there is a link between an expanding global division of labor and the relative wage in which trade plays a fundamental part. Although our wage data come entirely from the US, the specification of intensity of division of labor in the model is defined with respect to the world market as a whole. ${ }^{10}$ Thus, we choose to focus on variables that we hope to be reasonable measures of the extent of the global division of labor. In the model, the increasing returns at the macroeconomic level derive from the presence of greater variety in intermediate inputs, suggesting that we should focus on industrial intermediates. ${ }^{11}$ However, the available data are far from perfect measures of this variable. Although we considered a number of variables, we ultimately define intermediate trade as either intermediate trade excluding oil and intermediate trade excluding oil and motor vehicles. ${ }^{12}$ In both cases we define this variable as total world trade in the category as a percentage of world

9 These measures are derived from the annual March Current Population Survey, produced by the Bureau of the Census for the Bureau of Labor Statistics. Baldwin and Cain (2000) provide details of the construction of these variables.

10 This, in a sense is the fundamental point of Ethier's (1982) paper which, after all, is called: "National and International Returns to Scale in the Modern Theory of International Trade".

${ }^{11}$ Note that this is essentially what Borjas/ Ramey focus on, however, where they use net trade in intermediates for the US, the theoretical framework motivating our analysis suggests total global trade in intermediate goods.

12 These data are taken from the United Nation's COMTRADE database, as further processed and reported in the Global Trade Analysis Project database, version 5.2. 
GDP. All variables are analyzed in logarithmic form and are illustrated in Figure 3 (intermediate good trade).

Finally, the distinctive element of the Ethier model, and the element that renders the link between trade and the relative wages ambiguous, is the link between trade and macroeconomic productivity via the increased division of labor (i.e. Y oung-style roundaboutness). There is, of course, a sizable literature on the link between trade and growth focussing primarily on exports and, sometimes, on exports and imports separately..$^{13}$ In that analysis, trade is usually seen as affecting growth by its effect on capital accumulation. However, where that literature is interested in growth per se, the Ethier model suggests that the link is between trade and increased productivity. Thus, we attempt to introduce this element by including a measure of total factor productivity (TFP) in our analysis. Specifically, we consider measures of TFP for both manufacturing as a whole and for intermediate goods. ${ }^{14}$ These series are illustrated in Figure 4.

O ur model predicts that: (1) there should be a long run equilibrium relationship between international trade, TFP, and the skill premium, (2) within that relationship trade shocks should raise productivity, and (3) the effect of trade on wages is mediated by its effect on productivity and theoretically ambiguous. As we have just described, we have two alternative variables for each theoretical variable. We examine all 8 possible three variable systems consisting of one of the trade variables, one of the productivity variables and one of the wage variables. In each case we test for a long run relationship by looking for co-integration

\footnotetext{
${ }^{13}$ Most of this literature focuses on developing countries (for a survey, see A hmad, 2001). However, a number of papers have examined the case of industrial countries as well (e.g. Kunst and Marin, 1989; Marin, 1992, and Y amada, 1998). In addition, the recent paper by Atesoglu and Vilasuso (2003) focuses exclusively on the United States. The earlier work pretty uniformly found little evidence of export-led growth, but more recent studies, based on newer econometric methodologies, produce more supportive results. Commonly these more recent studies find evidence of a two-way relationship between exports and growth.

${ }^{14}$ We use two measures of productivity, both taken from the Bureau of Labor Statistics Major Sector Multifactor Productivity Series. These are productivity for intermediate goods, as proxied by industrial machinery and computer equipment (Series Id: MPU323503 (B), Multifactor Productivity Index 1996 = 100, Ind. Machinery,Comp.Eq.SIC35), and all manufacturing (Series Id: MPU300003 (B), Multifactor Productivity Index, 1996 = 100, Manufacturing).
} 
between the three series. We test for whether trade shocks raise productivity via tests on the coefficients of any existing cointegrating relationships and also by examining the generalized impulse response functions (GIRFs) of the various three variable systems. To investigate whether the relationship between trade and wages is mediated by productivity we compare the GIRFs of the three variable system to those of a two variable system consisting only of trade and wages.

Practically, the first step in testing for cointegration is to determine the order of integration of the series under study. We do so both by using augmented Dickey-Fuller (ADF) tests, where the null hypothesis is that the series contains a unit root, and KPSS tests where the null hypothesis is that the series is stationary. The results of these tests are presented in Table1. Panel A shows that the ADF tests fails to reject the hypothesis that each of the 6 variables has a unit root in their $\log$ levels, but rejects the same hypothesis in their growth rates. These results are mirrored almost exactly by the KPSS tests in panel B where the hypothesis that the log levels of the variables is stationary is rejected in all 6 cases, while the same hypothesis applied to the growth rates cannot be rejected in 5 of the 6 cases. The only place the tests conflict is on the question of whether the growth rate of our first wage variable is stationary (AD F says yes, KPSS says no). As a "tiebreaker" we use a Phillips-Perron test, which rejects the null of a unit root in the growth rate of this variable at the 0.01 level. We thus conclude that all 6 of our variables are difference stationary and proceed to test for the cointegration between trade productivity and wages that our model implies.

O ur cointegration tests use the now standard Johansen technique. We assume there is an intercept both in the cointegrating regression and in the VAR. We use 4 lagged difference terms in the VAR. Table 2 shows that in all eight possible three variable systems, the null hypothesis of no cointegrating vectors is rejected while the null hypothesis of a single co-integrating vector is never rejected. This is strong evidence in favor of our model's prediction that there should be a long run relationship between trade, productivity and wages. In each of the 8 cases there is a linear combination of the three variables that is stationary, meaning that there is an equilibrium relationship imposing limits on 
their individual movements.

As noted, the one more specific prediction of our model is that innovations to trade should raise productivity. We can test this hypothesis by means of testing coefficients in the single cointegrating relation found for each three variable system. The coefficients of the cointegrating relationship are not identified and require some normalization to interpret them. Generally, one of the variables has its coefficient normalized to 1.0. In our case we normalize the coefficient on productivity to 1.0 and then arrange the normalized coefficients to show the relationship between trade, wages and productivity. This is done for each of the 8 three variable systems and the results are reported in Table 3 . The Johansen procedure also provides asymptotic standard errors for the normalized coefficients and from these we can conduct asymptotic significance tests.

In all 8 systems the long run effect of trade on productivity (controlling for the effect of wages) is estimated to be positive and in 6 of the 8 cases the positive effect is significant at the 0.01 level. This lends further support to our model in that we find very strong evidence that increased trade raises productivity.

We now turn to the dynamic responses to shocks in our three variable systems. Given that in each case, the variables are all I(1) and there is a cointegrating relationship between them, the $\mathrm{G}$ ranger representation theorem states that the data can be validly modeled as a vector error correction (VEC) model. A VEC is a VAR in the growth rates with the lagged cointegrating relation included in each equation of the system as an additional explanatory variable. Put more precisely, let the data at time t be written in the $\mathrm{k} \times 1$ vector $\mathrm{X}_{\mathrm{t}}$ and let $\alpha$ be the vector of cointegrating coefficients. Then the cointegrating relationship can be written as $\alpha^{\prime} X_{t}$. The VEC for these data can be written as: $\Delta X_{t}=\gamma\left(\alpha^{\prime} X_{t-1}\right)+\sum \theta_{i} \Delta X_{t-i}+\varepsilon_{t}$ where the $\theta_{i}$ terms are $\mathrm{k} \times \mathrm{k}$ coefficient matrices and $\gamma$ is a $\mathrm{k} \times 1$ coefficient vector which shows how the growth rates of the variables respond to movements in the cointegrating relation.

We estimate a VEC representation for all 8 of our three variable systems 
using 4 lags of the growth rates. In each case we then study the responses of each variable in the system to a shock in one of the variables. We are especially interested in how productivity responds to trade shocks. We compute generalized impulse response functions which show the effect of a time $t$ innovation in one series on the behavior of another series (or itself) at times $t+i$. The GIRF accomplishes this in a way that does not depend on the ordering of the series. We also consider the cumulative effect of a shock via the accumulated GIR's of a system. These are simply the moving sum of the past impulse responses. Table 4 presents summaries of these accumulated GIR's. In particular, note that in all 8 cases, the cumulative effect of a trade shock on productivity is positive, reinforcing the result found above using the normalized cointegrating coefficients.

All in all there is a very consistent qualitative pattern in the accumulated GIR's across the 8 estimated VEC systems in that the sign of the accumulated effects do not vary across models. From the table we see that, wage shocks raise productivity and lower trade, productivity shocks raise productivity and lower trade, and that besides raising productivity, trade shocks also raise wages (the skill premium). Thus even when allowing for the possible mediating effect of productivity, trade innovations are associated with higher skill premiums.

Given that all 8 VEC's have the same pattern of results, we choose one particular system to discuss in more detail. Figure 5 shows the 10 period GIRFs for the three variable systems LWINTT2 LTFPINT LSP2 while Figure 6 shows the moving sum of those responses (i.e. the accumulated GIR). Table 5 provides information about how important movements in one variable are in explaining variation in the other variables by reporting on the eight period variance decomposition of the system.

Variance decompositions attribute fluctuations in one of the variables into the fractions attributable to shocks to each of the variables in the system. This is a way to gauge the overall importance of innovations in a variable to the 
evolution of the variables in the model..$^{15}$ We can see from the Table that trade shocks are relatively important for explaining movements in productivity (the average fraction of variation explained is around $40 \%$ ), while they are less important for explaining movements in the skill premium (the average fraction of variation explained is around $11 \%$ ). The main factor explaining variation in the skill premium is its own innovations as innovations to the skill premium explain around $75 \%$ of its own variation.

The final prediction of our model to consider here is whether the estimated effect of trade on wages would be different if the productivity variable was excluded. To address this issue we take the three variables system analyzed above and drop the productivity variable (LTFPINT) leaving a bivariate trade wages (LWINTT2 LSP2) model. Figures 7 and 8 present the GIRF's and accumulated G IR's for this bivariate VEC while Table 6 displays the 8 period variance decompositions. It is clear that ignoring productivity gives an inflated notion of the size of the effect trade shocks have on wages. The GIRF here shows that the effect of a trade shock on wages increases over time in a way not seen in the three variable model. This response causes the accumulated effects of a trade shock to be over $50 \%$ higher in the bivariate case than in the trivariate case. The variance decompositions show an even greater disparity in that the fraction of the variation in wages explained by trade shocks rises to an average of around $35 \%$ in the bivariate model compared to around $11 \%$ in our preferred trivariate model. These results show that bivariate evidence common in the literature of the effect of trade on wages should be taken with a grain (or two) of salt.

\footnotetext{
${ }^{15}$ Variance decompositions use the Cholesky orthogonalization and do depend on the ordering of the data. Here we use the ordering implied by our theory that Trade shocks causally come first followed by productivity and then wage shocks.
} 


\section{SUMMARY AND DIRECTIONS FOR FUTURE WORK}

In this paper we have argued that more attention needs to be given to NorthNorth trade in the literature on trade and labor markets. Such trade is considerably larger in magnitude than the North-South trade that implicitly motivates much of the existing research. In this context, we follow an expanding body of research on directions of trade in suggesting that frameworks alternative to the strict HOS model and its extensions should be explored. Thus, in section I we develop such a model, which has the implication that trade volumes are a potentially important explanatory variable when attempting to understand the link between globalization and wages. Section II presents an exploratory empirical study of this relationship. The key check on the plausibility of the model is the link between trade and TFP. If this relationship did not appear, we would take this as strong evidence against the Ethier model, or at least our empirical implementation of the model. In fact, this implication of the model receives strong support from our data. Turning to the link between trade and the skill premium, the model makes no prediction except that there should be a relationship. Here, again conditional on our empirical implementation (in particular the highly aggregate nature of the data we use), we find evidence of a positive relationship between trade and the skill premium. Interestingly, we find that the relationship is weaker than would be implied without taking into account the relationship between trade and TFP. Nonetheless, the magnitude of the effect is larger than most existing estimates, and appears to be larger than the profession's aggregate prior on that relationship.

We interpret our results not as definitive, but rather as suggestive of a need for additional work combining models of North-North trade with time series methods. As such, this paper should be viewed as exploratory. We see it as contributing to the growing body of research (in regional economics and macroeconomics, as well as trade) suggesting that models based on explicit attention to division of labor issues play an essential role in motivating and framing empirical research on trade. 


\section{References}

Ahmad, Jaleel (2001). "Causality Between Exports and Economic Growth: What do the Econometric Studies Tell Us?”. Pacific E conomic Review; V.6-\#1, pp. 147-167.

Antweiler, Werner and D aniel Trefler (2002). "Increasing Returns and All That: A View from Trade". A merican E conomic Review; V.92-\#1, pp. 93-119.

Atesoglu, H. Sonmez and Jon Vilasuso (1999). "A Band Spectral Analysis of Exports and Economic Growth in the United States". Review of International E conomics; V.7-\#1, pp. 140-152.

Baldwin, Robert and Glen Cain (2000). "Shifts in Relative US Wages: The Role of Trade, Technology and Factor Endowments". Review of E conomics and Statistics; V.82-\#4, pp. 580-595.

Borjas, G eorge and Valerie Ramey (1994). "The Relationship between Wage Inequality and International Trade". In J.H. Bergstrand, T.F. Cosimano, J.W. Houck, and R.G. Sheehan, eds. The C hanging D istribution of Income in an 0 pen U.S. E conomy. Amsterdam: North-Holland, pp. 217-241.

Buchanan, James and Y ong Y oon, eds. (1994). T he Return to Increasing Returns. Ann Arbor: University of Michigan Press.

Burda, Michael and Barbara D luhosch (2002). “Fragmentation, G lobalization and Labour Markets". In D avid Greenaway, Richard Upward, and Katherine Wakelin, eds. Trade, Investment, Migration and L abour Mark et A djustment. Basingstoke: Plagrave Macmillan, pp. 47-65.

Brander, James and Barbara Spencer (1988). "Unionized Oligopoly and International Trade Policy" . Journal of International E conomics; V.24-\#3/ 4, pp. 217-234.

D eardorff, Alan (2001). "Fragmentation across Cones". in S.W. Arndt and H. Kierzkowski, eds., Fragmentation: N ew Production Patterns in the W orld E conomy. Oxford: Oxford University Press, pp. 35-51. 
Dixit, Avinash and Joseph Stiglitz (1977). "Monopolistic Competition and O ptimum Product D iversity". A merican E conomic Review; V.67-\#3, pp. 297308.

Dluhosch, Barbara (2000). Industrial L ocation and $\mathrm{E}$ conomic Integration: C entrifugal and $C$ entripetal $\mathrm{F}$ orces in the $\mathrm{N}$ ew $\mathrm{E}$ urope. Cheltenham: Edward Elgar.

Ethier, Wilfred (1982). "National and International Returns to Scale in the Modern Theory of International Trade". A merican E conomic Review; V.72-\#3, pp. 388-405.

Feenstra, Robert and G ordon Hanson (1996). "Foreign Investment, O utsourcing and Relative Wages". in R. Feenstra, G. Grossman and D. Irwin, eds. The Political E conomy of T rade Policy. Cambridge: MIT, pp. 89-127.

Feenstra, Robert and Gordon Hanson (1997). "Foreign D irect Investment and Relative Wages: Evidence from Mexico's Maquiladoras". Journal of International E conomic; V.42-\#3/ 4, pp. 371-393.

Feenstra, Robert and G ordon Hanson (1999). "Productivity Measurement and the Impact of Trade and Technology on Wages: Estimates for the US, 19721990". Q uarterly Journal of E conomics; V.114-\#3, pp. 907-940.

Francois, J.F., "Global Production and Trade: Factor Migration and Commercial Policy with International Scale Economies." International E œnomic R eview, August 1994.

Francois, Joseph and D ouglas Nelson (2002). "A G eometry of Specialization". E onomic Journal; V.112-\#481, pp. 648-677.

Francois, Joseph and D ouglas Nelson (2001). "Victims of Progress: Economic Integration, Specialization and Wages for Unskilled Labour". CE PR D iscussion Paper, \# D P2527. 
Gaston, Noel and Daniel Trefler (1995). "Union Wage Sensitivity to Trade and Protection: Theory and Evidence." Journal of International E conomics; V.39\#1/2, pp.1-25.

G rossman, Gene (1984). "International Competition and the Unionized Sector". Canadian Journal of $\mathrm{E}$ œnomic; V.17-\#3, pp. 541-556.

Harrigan, James (2003). "Specialzation and the Volume of Trade: D o the D ata O bey the Laws". In E. Kwan Choi and James Harrigan, eds. H andbook of International Trade. Oxford: Blackwell, pp. 85-118.

Jones, Ronald and Henryk Kierzkowski (2001). "A Framework for Fragmentation". In S. Arndt and H. Kierzkowski, eds. Fragmentation: $\mathrm{N}$ ew Production Patterns in the W orld E conomy. New York: Oxford University Press, pp. 17-34.

Kohler, Wilhelm (2003). "The Distributional Effects of International Fragmentation”. G erman E conomic R eview; V.4-\#1, pp. 89-120.

Krugman, Paul (1995). D evelopment, G eography, and E conomic Theory. Cambridge: MIT Press.

Kunst, Robert and D alia Marin (1989). "On Exports and Productivity: A Causal Analysis". Review of E conomics and Statistic; V.71-\#4, pp. 699-703.

Lawrence, Colin and Robert Lawrence (1985). "Manufacturing Wage Dispersion: An End Game Interpretation”. B Brookings Papers on E conomic A civity; \#1, pp. 47-106.

Lovely, Mary and D ouglas Nelson (2000). "Marginal Intra Industry Trade and Labour Adjustment”. R eview of International E conomic;; V.8-\#3, pp. 436-447.

Marin, D alia (1992). "Is the Export-led Growth Hypothesis Valid for Industrialized Countries?”. Review of $\mathrm{E}$ conomics and Statistic; V.74-\#4, pp. 678688. 
Markusen, James (1990). "Micro-foundations of External Economies". Canadian Journal of E onomics; V.23-\#3, pp. 495-508.

Markusen, James and Anthony Venables (1997). "The Role of Multinational Firms in the Wage-G ap D ebate". Review of International E conomics; V.5-\#4, pp.435-451.

Markusen, James and Anthony Venables (1999). "Multinational Production, Skilled Labor, and Real Wages". in R. Baldwin and J. Francois, eds. D ynamic Issues in Commercial Policy A nalysis. Cambridge: CUP, pp. 138-172.

Mezzetti, Claudio and Elias Dinopoulos (1991). "D omestic Unionization and Import Competition". Journal of International E conomics; V.31-\#1/ 2, pp. 79-100.

Roemer, Paul (1987). "Growth Based on Increasing Returns to Specialization". A merican E conomic Review; V.77-\#2, pp. 56-62.

Trefler, D aniel (1995). "The Case of Missing Trade and Other Mysteries". A merican E conomic Review; V.85-\#5, pp. 1029-1046.

Spence, A. Michael (1976). "Product Selection, Fixed Costs, and Monopolistic Competition”. Review of E onomic Studies; V.43-\#2, pp. 217-235.

Yamada, Hiroshi (1998). "A Note on the Causality between Export and Productivity: An Empirical Reexamination". E conomics L etters; 61-\#1, pp. 111114. 


\section{Wages by Skill Category}

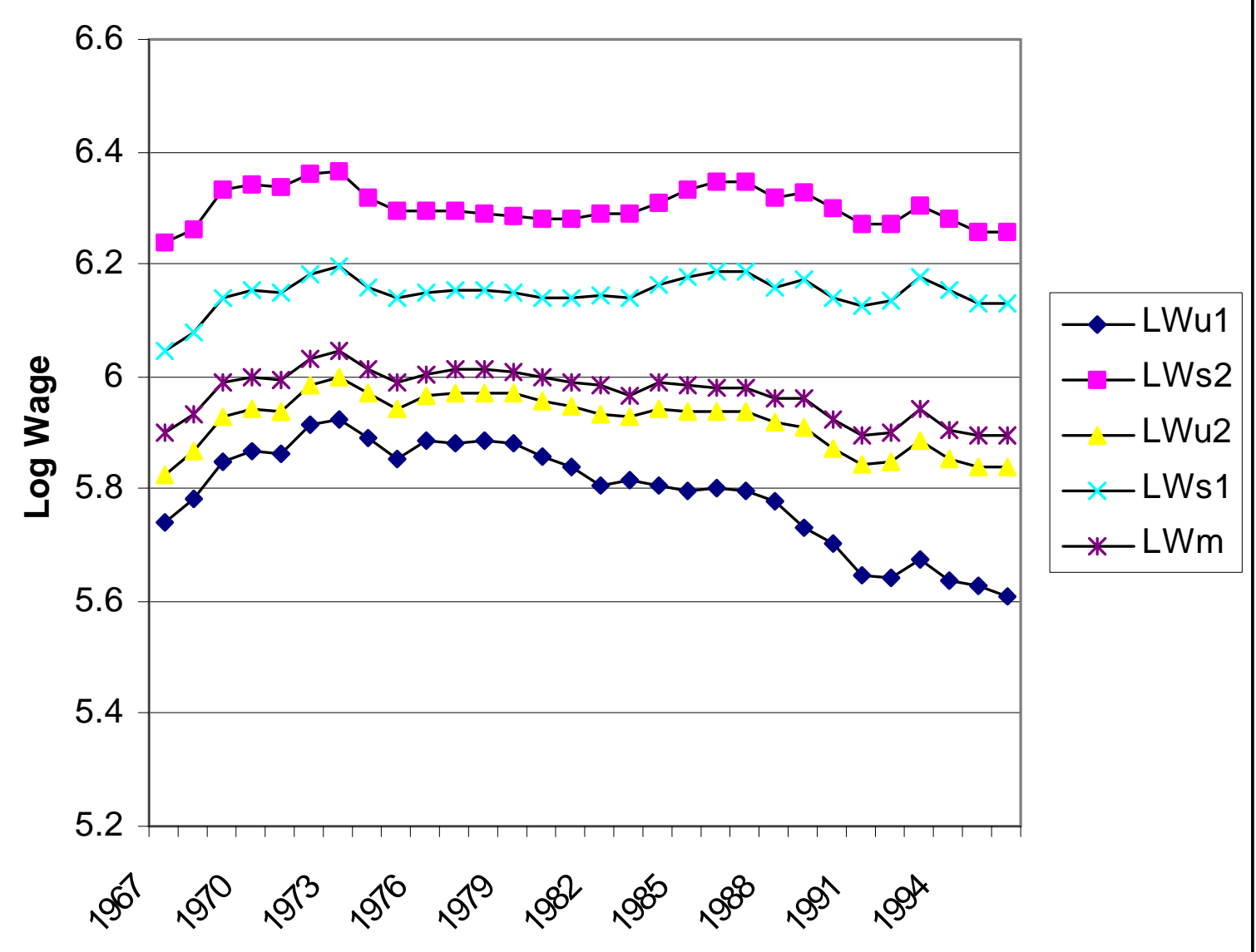

Figure 1 


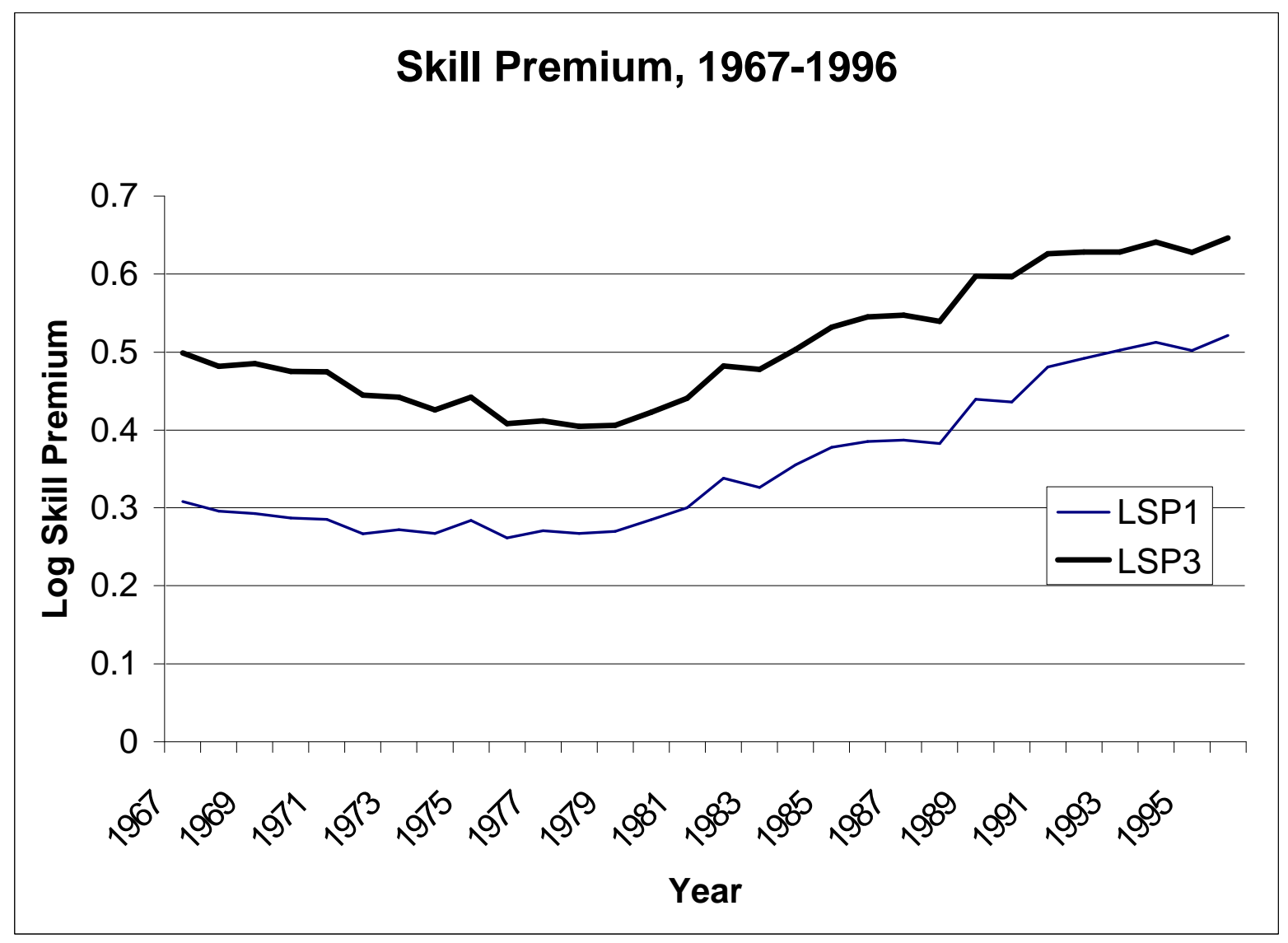

Figure 2 


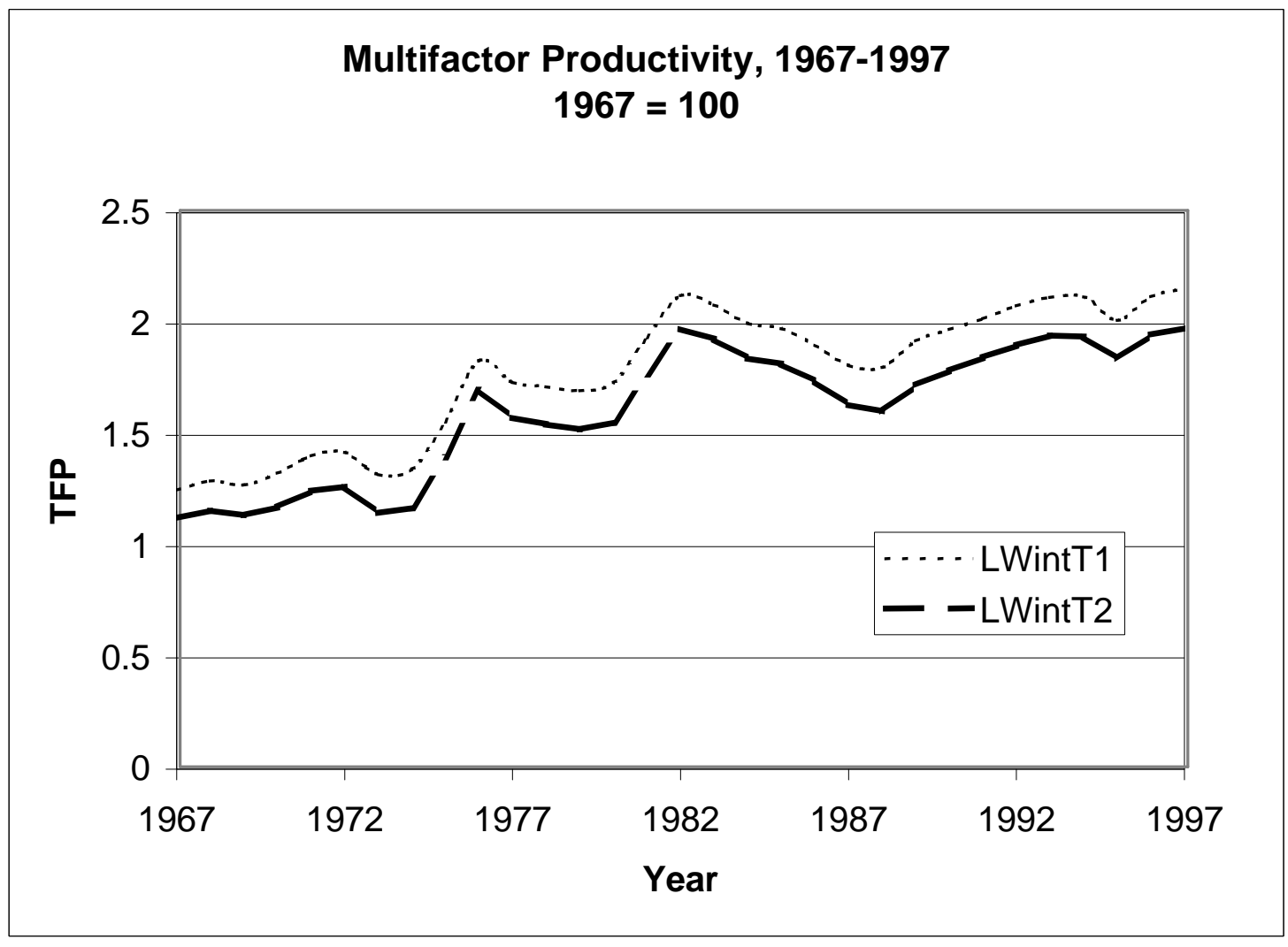

Figure 3 


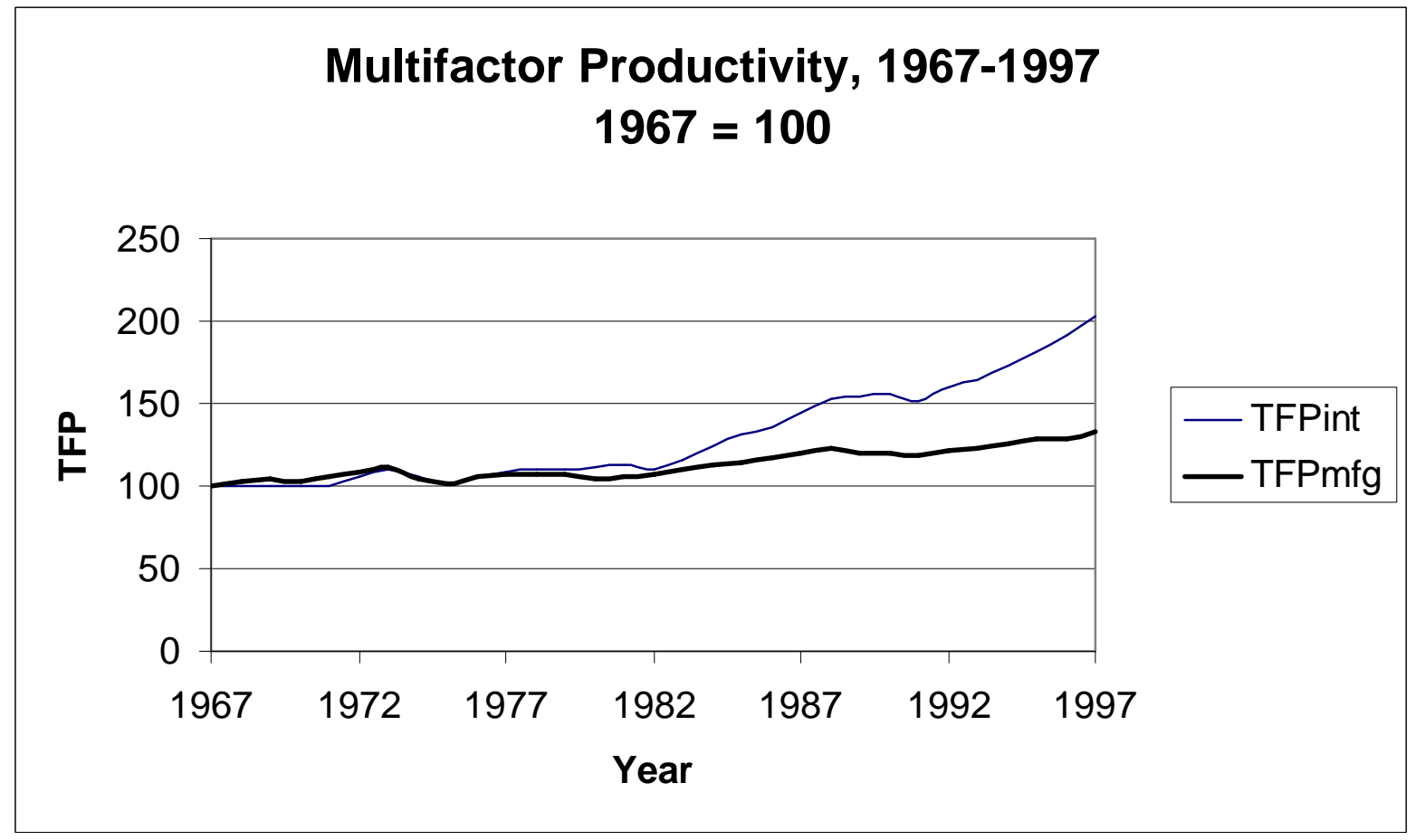

Figure 4 
Figure 5. GIRFs for the system LWINTT2 LTFPINT LSP2

Response to Generalized One S.D. Innovations
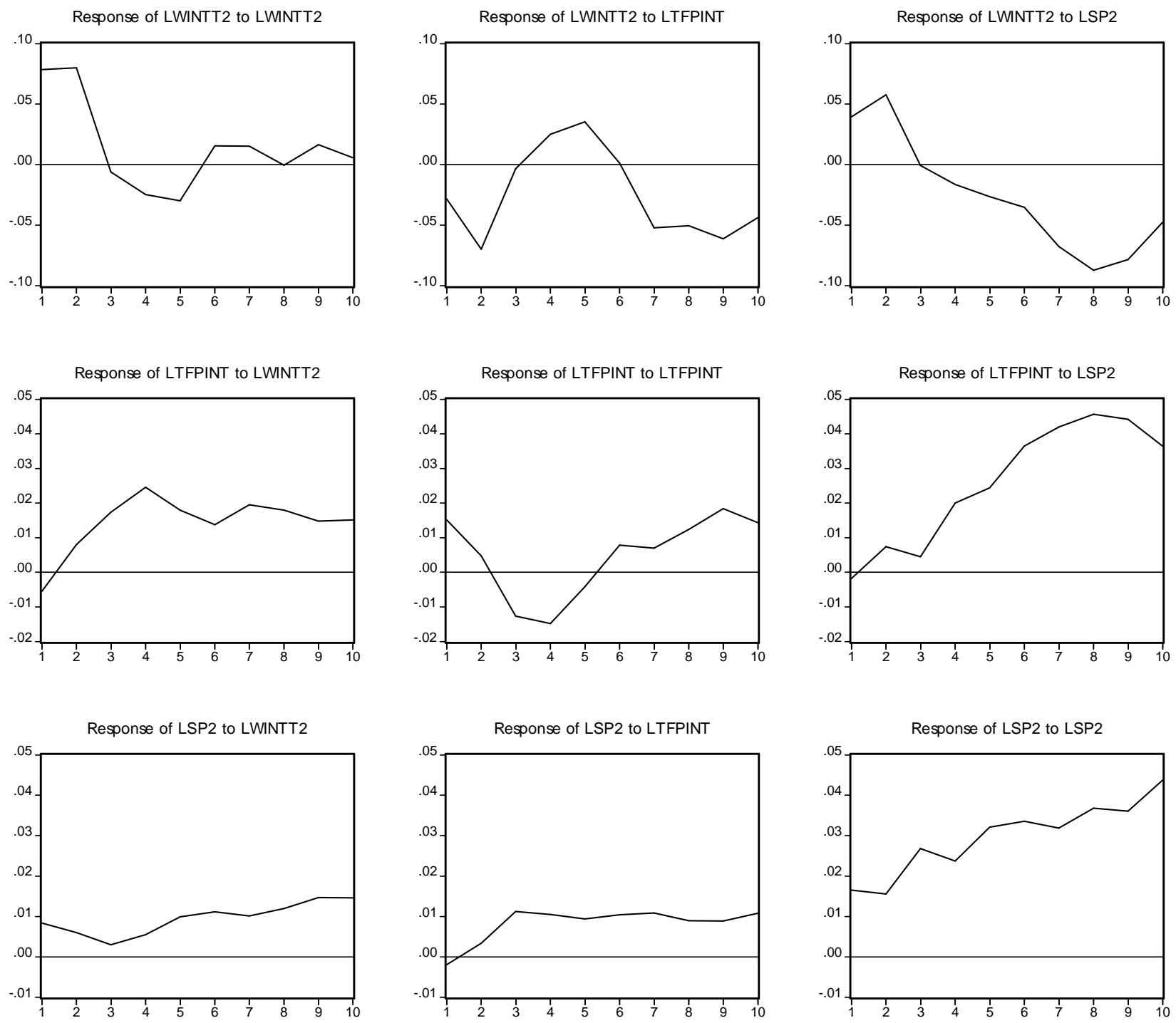
Figure 6. Accumulated generalized responses for the system LWINTT2 LTFPINT LSP2

Accumulated Response to Generalized One S.D. Innovations

Accumulated Response of LWINTT2 to LWINTT2

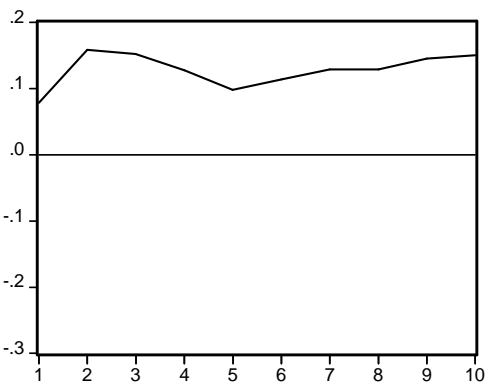

Accumulated Response of LTFPINT to LWINTT2

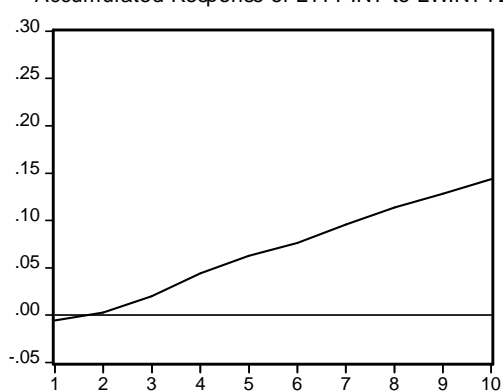

Accumulated Response of LSP2 to LWINTT2

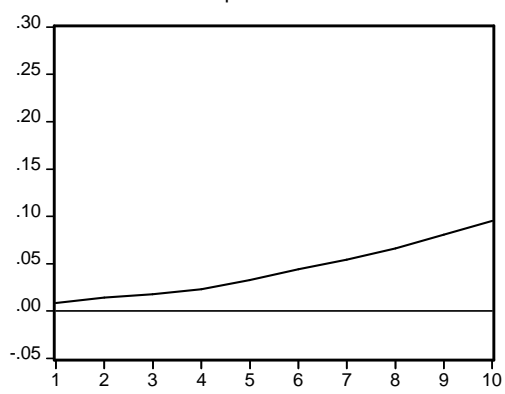

Accumulated Response of LWINTT2 to LTFPINT

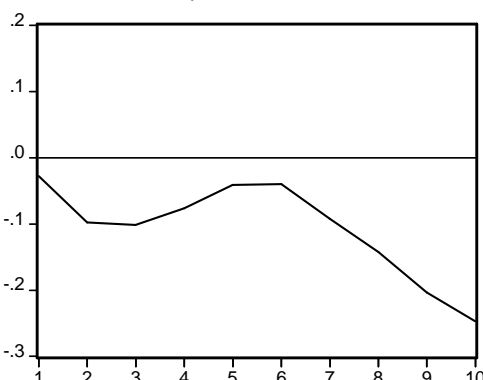

Accumulated Response of LTFPINT to LTFPINT

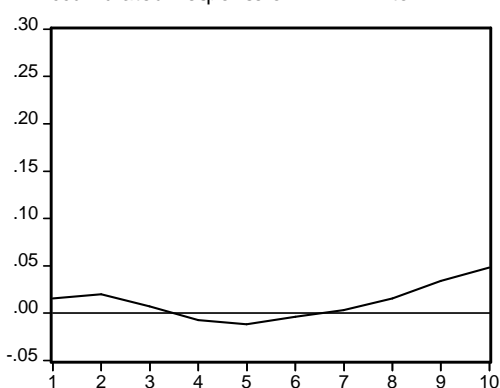

Accumulated Response of LSP2 to LTFPINT

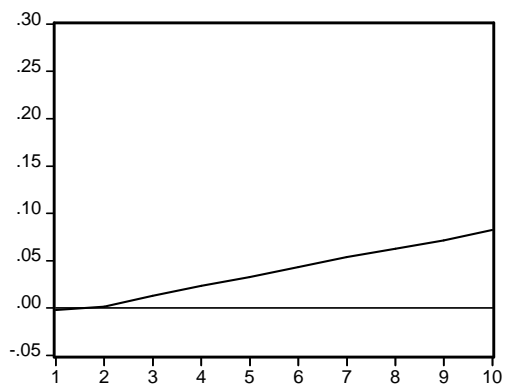

Accumulated Response of LWINTT2 to LSP2

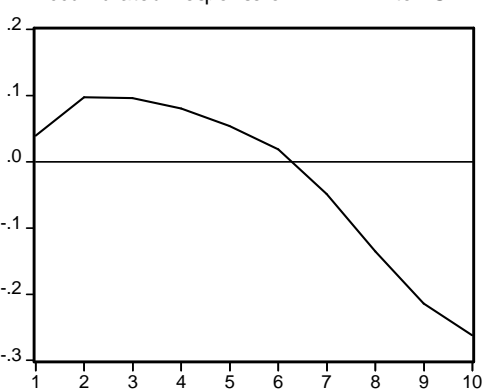

Accumulated Response of LTFPINT to LSP2

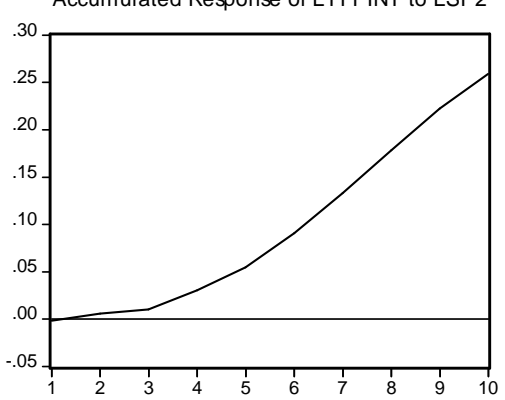

Accumulated Response of LSP2 to LSP2

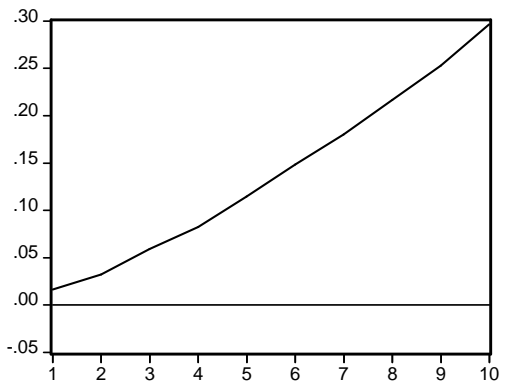


Figure 7. GIRF's for the system LWINTT2 LSP2

Response to Generalized One S.D. Innovations
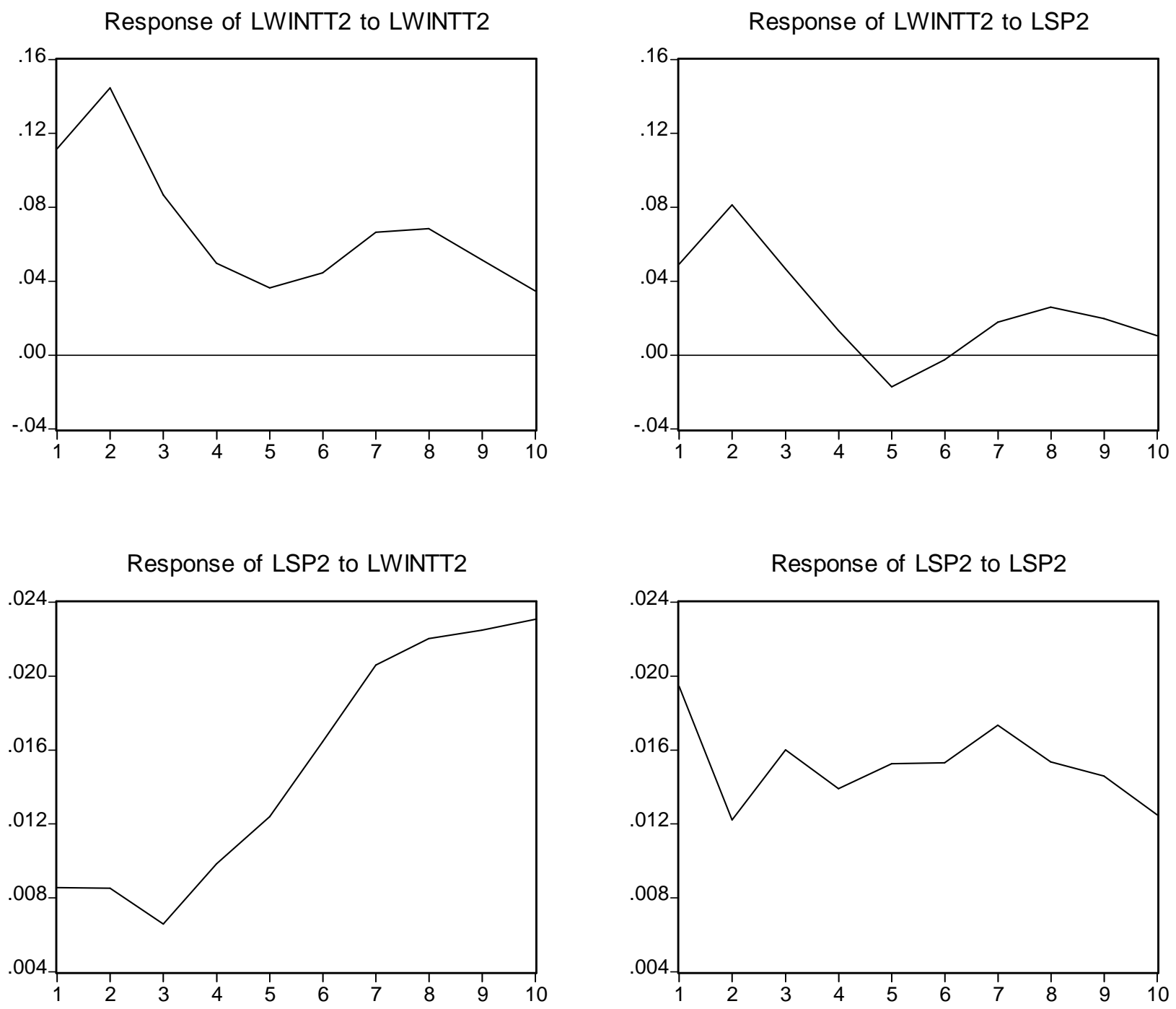
Figure 8. Accumulated generalized responses for the system LWINTT2 LSP2

Accumulated Response to Generalized One S.D. Innovations

Accumulated Response of LWINTT2 to LWINTT2

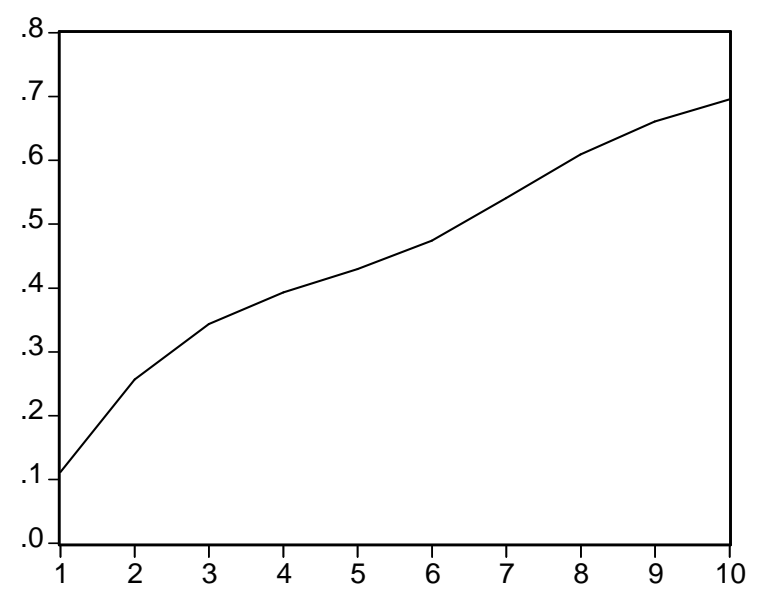

Accumulated Response of LSP2 to LWINTT2

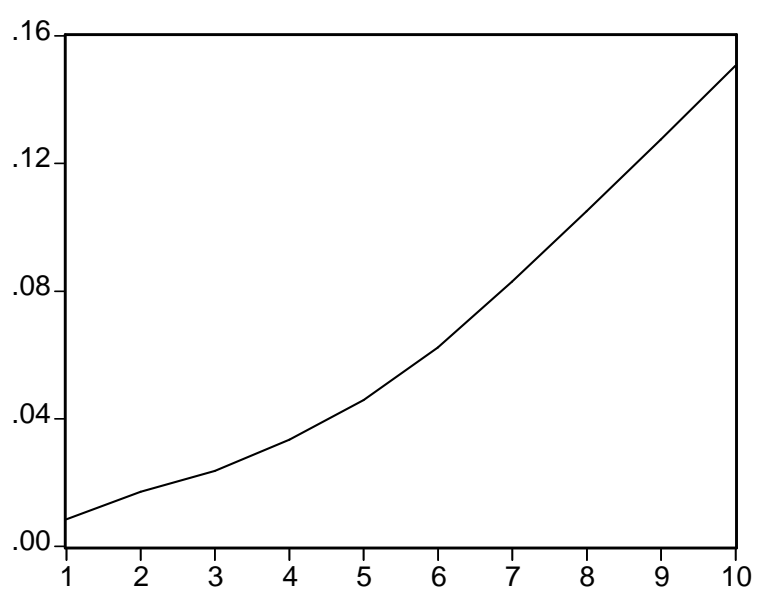

Accumulated Response of LWINTT2 to LSP2

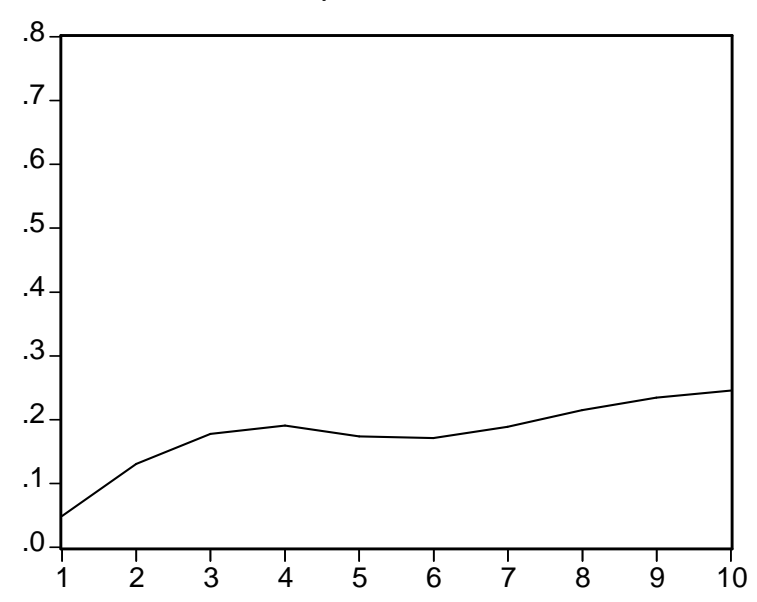

Accumulated Response of LSP2 to LSP2

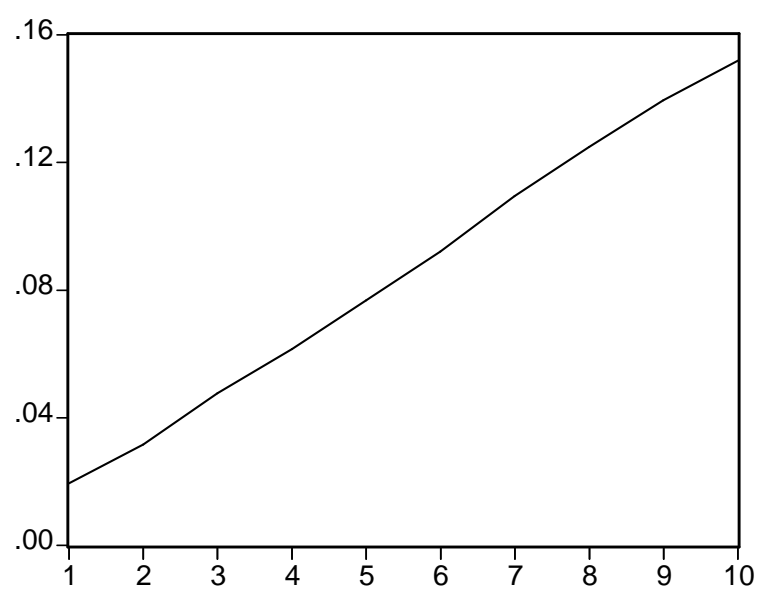




\section{A: Augmented Dickey-Fuller Tests ${ }^{1}$}

Variable

AD F t-statistic testing Ho: Variable has a unit root

Levels

$-1.01$

0.47

$-1.59$

$-1.51$

0.69

2.10 $1^{\text {st }}$ Differences

$-6.14 * * *$

$-5.46^{* * *}$

$-4.79 * * *$

$-4.81 * * *$

$-4.89 * * *$

$-3.67 * *$

B: KPSS Tests ${ }^{2}$

Variable

AD F t-statistic testing Ho: Variable is stationary

Levels

$1^{\text {st }} \mathrm{D}$ ifferences

LSP1

$0.61 * *$

$0.47 * *$

LSP2

$0.53^{* *}$

0.44

LWINTT1

$0.65^{* *}$

0.38

LWINTT2

$0.64^{* *}$

0.39

LTFPMFG

$0.69 * *$

0.32

LTFPINT

$0.70 * *$

0.45

1. Lag length chosen by Schwartz Information Criterion

2. Spectral estimation is via the Bartlett kernel, bandwidth is automatically selected using the Newey-West criterion. ** indicates rejection of the null at the 0.05 level, ${ }^{* * *}$ at the 0.01 level. All tests performed using EVIEWS4. 
Table 2: Cointegration Tests

\begin{tabular}{|c|c|c|c|c|}
\hline System & Statistic & Ho: $r=0$ & Ho: $r<=1$ & Ho: $r<=2$ \\
\hline \multicolumn{5}{|l|}{ LWINTT1 } \\
\hline LTFPINT & Trace & $39.01 * * *$ & 8.16 & 1.41 \\
\hline LSP1 & Max-Eigen & $30.86^{* * *}$ & 6.73 & 1.41 \\
\hline \multicolumn{5}{|l|}{ LWINTT1 } \\
\hline LTFPINT & Trace & $52.98 * * *$ & 12.54 & 1.57 \\
\hline LSP2 & Max-Eigen & $40.44^{* * *}$ & 10.97 & 1.57 \\
\hline \multicolumn{5}{|l|}{ LWINTT1 } \\
\hline LTFMFG & Trace & $30.72^{* *}$ & 8.85 & 0.81 \\
\hline LSP1 & Max-Eigen & $21.87 * *$ & 8.05 & 0.81 \\
\hline \multicolumn{5}{|l|}{ LWINTT1 } \\
\hline LTFPMFG & Trace & $36.25^{* *}$ & 12.18 & 0.01 \\
\hline LSP2 & Max-Eigen & 24.06** & 12.17 & 0.01 \\
\hline \multicolumn{5}{|l|}{ LWINTT2 } \\
\hline LTFPINT & Trace & $40.12^{* * *}$ & 7.96 & 1.46 \\
\hline LSP1 & Max-Eigen & 32.16 *** & 6.49 & 1.46 \\
\hline \multicolumn{5}{|l|}{ LWINTT2 } \\
\hline LTFPINT & Trace & $57.27 * * *$ & 13.49 & 1.86 \\
\hline LSP2 & Max-Eigen & $43.78^{* * *}$ & 11.63 & 1.86 \\
\hline \multicolumn{5}{|l|}{ LWINTT2 } \\
\hline LTFMFG & Trace & $30.81 * *$ & 9.03 & 0.93 \\
\hline LSP1 & Max-Eigen & $21.77 * *$ & 8.10 & 0.93 \\
\hline \multicolumn{5}{|l|}{ LWINTT2 } \\
\hline LTFPMFG & Trace & 35.31** & 11.86 & 0.04 \\
\hline LSP2 & Max-Eigen & $23.44^{* *}$ & 11.81 & 0.04 \\
\hline
\end{tabular}

*** indicates rejection of the null at the 0.01 level, $* *$ at the 0.05 level. All tests assume an intercept both in the cointegrating relation and the VAR, and use 4 lagged difference terms. All tests performed using EVIEWS4 
Table 3: $\quad$ The (normalized) Cointegrating Relations from the 8 Three Variables Systems

$$
\begin{aligned}
& \text { LTFPINT }=0.220 \text { LWINTT1 + } 1.944 \text { LSP1 }+3.100 \\
& (0.033) \quad(0.061) \\
& \text { LTFPINT }=0.411 \text { LWINTT1 }+1.722 \text { LSP2 }+2.573 \\
& (0.021) \quad(0.047) \\
& \text { LTFPMFG }=\underset{(0.021)}{0.029 L W I N T T 1}+\frac{0.694 \text { LSP } 1+4.171}{(0.042)} \\
& \text { LTFPMFG }=0.117 \text { LWINTT } 1+0.603 \text { LSP2 }+3.952 \\
& (0.018) \quad(0.038)
\end{aligned}
$$

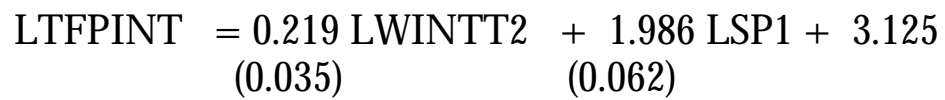

$$
\begin{aligned}
& \text { LTFPINT }=0.418 \text { LWINTT2 }+1.789 \text { LSP } 2+2.597 \\
& (0.023) \quad(0.047) \\
& \text { LTFPMFG }=0.029 \text { LWINTT } 2+0.711 \text { LSP } 1+4.168439 \\
& (0.021) \quad(0.042) \\
& \text { LTFPMFG }=0.114 \text { LWINTT } 2+0.629 \text { LSP } 2+3.962340 \\
& (0.019) \quad(0.039)
\end{aligned}
$$

Numbers in parentheses are asymptotic standard errors. 


\section{Table 4: $\quad$ Summarizing the 10 period Accumulated}

Generalized Impulse Responses for all 8 VEC Models:

Accumulated Response of TFP to a generalized TRADE shock: positive 8 of 8 times

Accumulated Response of TFP to a generalized SK ILL shock: positive 8 of 8 times

Accumulated Response of TFP to a generalized own shock: $\quad$ essentially zero 8 of 8 times

Accumulated Response of SKILL to a generalized TRADE shock: positive 8 of 8 times

Accumulated Response of SKILL to a generalized TFP shock: positive 8 of 8 times

Accumulated Response of SK ILL to a generalized own shock: positive 8 of 8 time

Accumulated Response of TRADE to a generalized TFP shock: negative 8 of 8 times Accumulated Response of TRADE to a generalized SKILL shock: negative 8 of 8 times Accumulated Response of TRADE to a generalized own shock: positive 8 of 8 time 
Table 5: $\quad$ Variance Decompositions for the system LWINTT2 LTFPINT LSP2 ${ }^{1}$

Variance D ecomposition of LWINTT2:

$\begin{array}{lcccl}\text { Period } & \text { S.E. } & \text { LWINTT2 } & \text { LTFPINT } & \text { LSP2 } \\ 1 & 0.078465 & 100.0000 & 0.000000 & 0.000000 \\ 2 & 0.122700 & 83.46771 & 12.89969 & 3.632606 \\ 3 & 0.123035 & 83.25832 & 13.05999 & 3.681693 \\ 4 & 0.126809 & 82.11587 & 14.19881 & 3.685324 \\ 5 & 0.133749 & 78.76291 & 16.64622 & 4.590868 \\ 6 & 0.143970 & 69.12483 & 14.62987 & 16.24530 \\ 7 & 0.174415 & 47.86192 & 18.21917 & 33.91890 \\ 8 & 0.206643 & 34.09729 & 19.82079 & 46.08192\end{array}$

Variance D ecomposition of LTFPINT:

$\begin{array}{lcccc}\text { Period } & \text { S.E. } & \text { LWINTT2 } & \text { LTFPINT } & \text { LSP2 } \\ 1 & 0.015144 & 12.90740 & 87.09260 & 0.000000 \\ 2 & 0.019241 & 25.18999 & 71.84871 & 2.961300 \\ 3 & 0.027162 & 53.41773 & 42.41768 & 4.164591 \\ 4 & 0.038319 & 67.85970 & 24.11315 & 8.027146 \\ 5 & 0.045901 & 62.55241 & 17.08795 & 20.35964 \\ 6 & 0.059873 & 42.01794 & 15.25321 & 42.72885 \\ 7 & 0.074113 & 34.34492 & 14.07197 & 51.58311 \\ 8 & 0.088870 & 27.96180 & 14.95111 & 57.08708\end{array}$

Variance D ecomposition of LSP2:

$\begin{array}{lcccc}\text { Period } & \text { S.E. } & \text { LWINTT2 } & \text { LTFPINT } & \text { LSP2 } \\ 1 & 0.016495 & 25.53232 & 0.470570 & 73.99711 \\ 2 & 0.023270 & 19.50577 & 6.701423 & 73.79281 \\ 3 & 0.039108 & 7.489355 & 13.62976 & 78.88088 \\ 4 & 0.047747 & 6.354028 & 16.94645 & 76.69953 \\ 5 & 0.059090 & 6.973182 & 16.60466 & 76.42216 \\ 6 & 0.069522 & 7.601041 & 16.95515 & 75.44381 \\ 7 & 0.077894 & 7.742931 & 17.48266 & 74.77441 \\ 8 & 0.087239 & 8.052522 & 16.57626 & 75.37121\end{array}$

1. VDC uses the Cholesky decomposition with ordering: LWINTT2 LTFPINT LSP2 
Variance D ecomposition of LWINTT2:

Period S.E. $\quad$ LWINTT2 LSP2

$\begin{array}{llll}1 & 0.111922 & 100.0000 & 0.000000 \\ 2 & 0.183980 & 98.83316 & 1.166843 \\ 3 & 0.203630 & 98.82728 & 1.172722 \\ 4 & 0.209861 & 98.68379 & 1.316206 \\ 5 & 0.216201 & 95.83598 & 4.164016 \\ 6 & 0.222102 & 94.83065 & 5.169350 \\ 7 & 0.232207 & 94.97314 & 5.026860 \\ 8 & 0.242121 & 95.34102 & 4.658985\end{array}$

Variance D ecomposition of LSP2:

$\begin{array}{lccl}\text { Period } & \text { S.E. } & \text { LWINTT2 } & \text { LSP2 } \\ & & & \\ 1 & 0.019443 & 19.36375 & 80.63625 \\ 2 & 0.023227 & 27.02928 & 72.97072 \\ 3 & 0.028213 & 23.77480 & 76.22520 \\ 4 & 0.031731 & 28.43304 & 71.56696 \\ 5 & 0.035772 & 34.37086 & 65.62914 \\ 6 & 0.040383 & 43.55979 & 56.44021 \\ 7 & 0.046262 & 53.01793 & 46.98207 \\ 8 & 0.051629 & 60.78768 & 39.21232\end{array}$

1. VDC uses the Cholesky decomposition with ordering: LWINTT2 LSP2 